\title{
Lead Exposure and Cardiovascular Disease among Young and Middle-Aged Adults
}

\author{
Emmanuel Obeng-Gyasi ${ }^{\mathbb{D}}$
}

Environmental Health and Safety Program, Department of Built Environment, North Carolina Agricultural \& Technical State University, Greensboro, NC 27411, USA; eobenggyasi@ncat.edu; Tel.: +1-336-285-3132

Received: 8 October 2019; Accepted: 5 November 2019; Published: 6 November 2019

\begin{abstract}
Lead and its effects on cardiovascular-related markers were explored in this cross-sectional study of young adults (18-44 years) and middle-aged adults (45-65 years) from the United States using the National Health and Nutrition Examination Survey (NHANES), 2009-2016. Degrees of exposure were created using blood lead level (BLL) as the biomarker of exposure based on the epidemiologically relevant threshold of BLL $>5 \mu \mathrm{g} / \mathrm{dL}$. The mean values, in addition to the percentages of people represented for the markers of interest (systolic blood pressure [SBP], diastolic blood pressure [DBP], gamma-glutamyl transferase [GGT], non-high-density lipoprotein cholesterol [non-HDL-C]) were explored. Among those exposed to lead, the likelihood of elevated clinical markers (as defined by clinically relevant thresholds of above normal) were examined using binary logistic regression. In exploring exposure at the $5 \mu \mathrm{g} / \mathrm{dL}$ levels, there were significant differences in all the mean variables of interest between young and middle-aged adults. The binary logistic regression showed young and middle-aged adults exposed to lead were significantly more likely to have elevated markers (apart from DBP). In all, lead affects cardiovascular-related markers in young and middle-aged U.S. adults and thus we must continue to monitor lead exposure to promote health.
\end{abstract}

Keywords: lead exposure; lead young adult; lead middle-aged adult; lead cardiovascular

\section{Introduction}

Lead exposure begins as early as pregnancy and can affect those exposed throughout their life as it persists in the blood and the bone [1,2]. Exposure to lead may occur in many settings via water, air, soil, dust, and food [3-6] and may subsequently induce toxic pathology in many organ systems within the human body [7-10].

Cardiovascular diseases are the primary cause of mortality in the world [11]. Cardiovascularrelated markers include systolic blood pressure (SBP), for which a value of less than or equal to $120 \mathrm{~mm} \mathrm{Hg}$ is considered normal. An SBP reading of $130 \mathrm{~mm} \mathrm{Hg}$ or more is medically classified as stage I hypertension. Another marker of interest is diastolic blood pressure (DBP); clinically, a normal DBP must be less than $80 \mathrm{~mm} \mathrm{Hg}$. Values greater than or equal to $140 \mathrm{~mm} \mathrm{Hg}$ for SBP is considered stage II hypertension, while values greater than or equal to $90 \mathrm{~mm} \mathrm{Hg}$ is considered stage II for DBP. These guidelines by the American College of Cardiology (ACC) and the American Heart Association (AHA) recently replaced guidelines which had higher medical thresholds to reach these health classifications [12]. Lead exposure and its relation to hypertension have been demonstrated in the literature [8,12,13], with increases in blood lead level (BLL) increasing blood pressure [14-16].

Non-high-density lipoprotein cholesterol (non-HDL-C), a measure of low-density lipoprotein (LDL) cholesterol and very low-density lipoprotein (VLDL) cholesterol, predicts heart disease risk better than markers such as LDL cholesterol [17]. A non-HDL-C value $>160 \mathrm{mg} / \mathrm{dL}$ is considered elevated $[18,19]$. The mechanisms by which lead alters cholesterol synthesis is still being studied, but it is potentially involved in promoting enzymes essential for cholesterol synthesis (enzymes such 
as 3-hydroxy-3-methyglutaryl coenzyme A [HMG CoA] reductase, farnesyl diphosphate synthase, squalene synthase, and lanosterol 14a-demethylase CYP51) while also inhibiting enzymes involved in its breakdown (e.g., $7 \alpha$-hydroxylase) [20].

Gamma-glutamyl transferase (GGT) is an enzyme that is present in hepatocytes, biliary epithelial cells, renal tubules, and the pancreas and intestine. GGT is a microsomal enzyme, and toxicants, drugs, or dietary alterations can induce its activity. It is also a sensitive marker for oxidative stress [21,22], a condition in which free reactive oxygen species (ROS) and free radicals cause potential biological damage [23].

Lead's effect on the cardiovascular system and cardiovascular-related markers has been well noted in the literature [24]. The mechanism by which lead induces hypertension may be related to oxidative stress, inflammation, alterations in the renin-angiotensin-aldosterone system, alteration of vasoactive and volume regulatory hormones, and nitric oxide dysregulation, among other mechanisms [24].

No level of lead exposure is safe, but exposure above the $5 \mu \mathrm{g} / \mathrm{dL}$ level has been widely accepted to be elevated in adults [25]. Age is also a key factor in lead exposure, as longer exposure results in worse health outcomes [26,27]. It is important to examine how the cardiovascular system of young adults and middle-aged adults are differentially affected by exposure to lead. To this effect, key cardiovascular-related markers, such as non-HDL-C, GGT, SBP, and DBP, can serve to inform about lead's effect among adults exposed at all levels and above the threshold considered elevated.

It is also key then to examine potential markers or mechanisms which may result in worse cardiovascular health. This study examines the effects of lead on the abovementioned cardiovascular-related markers in young adults and middle-aged adults, looking at both the associations between lead and these markers and the likelihood of elevated marker levels among those exposed to lead.

\section{Methods}

\subsection{Study Hypothesis}

This study hypothesized that lead exposure is associated with adverse alterations in oxidative stress (GGT), heart disease risk (non-HDL-C), and blood pressure (SBP and DBP) in middle-aged adults more so than younger adults, as they may have been exposed over a longer duration of time, thereby adversely altering their cardiovascular health. In addition, this study hypothesized that lead would be significantly associated with more adverse cardiovascular-related markers in middle-aged adults as compared to younger adults. The objective in this study was to investigate the effects of lead exposure by analyzing non-HDL-C, GGT, SBP, and DBP in young (18-44 years) and middle-aged (45-65 years) U.S. adults.

\subsection{Research Design}

The relationships between lead and SBP, DBP, GGT, and non-HDL-C were explored using the National Health and Nutrition Examination Survey (NHANES) 2009-2016, a representative sample of the noninstitutionalized U.S. population. Four sets of two-year cycle data were combined to build the dataset. Data from young adults and middle-aged adults were analyzed using guidelines provided by the 2009-2016 NHANES tutorial [9].

Metal assays were conducted using whole blood samples for the NHANES 2009-2016 at the National Center for Environmental Health (NCEH). Inductively coupled plasma mass spectrometry (ICP-MS) was used to measure BLLs with the lower limit being $0.07 \mu \mathrm{g} / \mathrm{L}$. Biochemistry markers were measured using a Beckman Synchron LX20 and Beckman UniCel ${ }^{\circledR}$ DxC800 Synchron (Collaborative Laboratory Services), including a Roche Modular P chemistry analyzer (University of Minnesota, Minneapolis, MN, USA). The data analysis was performed in Stata SE/15.0 (StataCorp, College Station, TX, USA), which permitted for the adjustment of sample weights, strata, and clusters in the complex design. 


\subsection{Statistical and Analytical Approaches}

The data from young and middle-aged adults were analyzed for the cardiovascular-related markers in this cross-sectional study. The level of elevated exposure was created using the BLL based on the epidemiologically relevant threshold of $5 \mu \mathrm{g} / \mathrm{dL}$. The mean values, in addition to the representative percentages for the markers of interest, were explored at the $5 \mu \mathrm{g} / \mathrm{dL}$ exposure level.

The likelihood of elevated clinical markers as defined by clinically relevant thresholds of exposure (SBP $>120 \mathrm{~mm} \mathrm{Hg}$ and DBP $>80 \mathrm{~mm} \mathrm{Hg}$ for blood pressure, GGT above the median of the dataset (18 U/L) for oxidative stress, and non-HDL-C $>160 \mathrm{mg} / \mathrm{dL}$ for heart disease risk) were explored via binary logistic regression. The clinical markers served as the dependent variables, while the independent variable was the blood lead levels.

In this study, individual models were used to explore each exposure-outcome variable in logistic regression. The data were adjusted for different combinations of gender, body mass index (BMI), income, ethnicity, alcohol consumption, and smoking based on the literature [28-32]. Where relevant with the complex design, weights were adjusted to ensure the analysis was representative of the noninstitutionalized U.S. general adult population. A Shapiro-Wilk test revealed that BLL was not normally distributed, so it was natural $\log$ transformed. A $p$-value $<0.05$ determined significance while a value of $p<0.10$ was deemed moderately significant.

\section{Results}

\subsection{Clinical Markers of Interest}

The clinical markers of interest in the young and middle-aged adults were analyzed to determine the mean values of the markers of interest among the two groups of adults. BLLs were more elevated in middle-aged adults than in younger adults, with SBP also following the same pattern. Further, concerning DBP, non-HDL-C, and GGT, higher values were found in the middle-aged adult group. Regarding BLL, SBP, DBP, non-HDL-C, and GGT there was a significant difference between young adults and middle-aged adults $(p<0.001)$. Table 1 summarizes these results.

Table 1. Variables of interest among categories of adults.

\begin{tabular}{ccccc}
\hline Variables & N Young Adults & Young Adults (SE) & $\begin{array}{c}\text { N Middle-Aged } \\
\text { Adults }\end{array}$ & $\begin{array}{c}\text { Middle-Aged } \\
\text { Adults (SE) }\end{array}$ \\
\hline BLL- $\mu$ g/dL (SE) & 7730 & $1.03(0.026)$ & 5744 & $1.62(0.044)$ \\
SBP-mmHg (SE) & 9757 & $115.27(0.201)$ & 7119 & $124.15(0.351)$ \\
DBP-mmHg (SE) & 9757 & $68.99(0.292)$ & 7119 & $72.99(0.262)$ \\
non-HDL-C-mg/dL (SE) & 10,165 & $132.74(0.636)$ & 7512 & $149.21(0.761)$ \\
GGT-U/L (SE) & 10,130 & $24.02(0.378)$ & 7489 & $30.87(0.723)$ \\
\hline
\end{tabular}

\subsection{Clinical Markers at Exposure Levels of BLL above $5 \mu \mathrm{g} / \mathrm{dL}$}

Mean levels of the clinical markers of interest among the adults in the two age groups exposed to BLLs above the $5 \mu \mathrm{g} / \mathrm{dL}$ threshold were explored. At the BLL of $>5 \mu \mathrm{g} / \mathrm{dL}$, SBP was more elevated as the age group increased. DBP, non-HDL-C, and GGT increased from young adulthood to middle age. At the BLL of $>5 \mu \mathrm{g} / \mathrm{dL}$, regarding DBP, there was a significant difference between young adults and middle-aged adults $(p=0.003)$.

For SBP at the $5 \mu \mathrm{g} / \mathrm{dL}$ level and above, there was a significant difference between young adults and middle-aged adults $(p<0.001)$. Regarding non-HDL-C, at the $5 \mu \mathrm{g} / \mathrm{dL}$ level, there were no significant differences. Finally, for GGT, there were no statistically significant differences at the $5 \mu \mathrm{g} / \mathrm{dL}$ level. The results can be found in Table 2 below. 
Table 2. How variables manifested at an exposure level of $5 \mu \mathrm{g} / \mathrm{dL}$ and above among adults.

\begin{tabular}{cccc}
\hline Variables at $\mathbf{5} \boldsymbol{\mu g} / \mathbf{d L}$ and above & N Total & Young Adults (SE) & Middle-Aged Adults (SE) \\
\hline $\mathrm{SBP}-\mathrm{mmHg}(\mathrm{SE})$ & 379 & $116.47(1.65)$ & $132.19(2.50)$ \\
$\mathrm{DBP}-\mathrm{mmHg}$ (SE) & 379 & $70.16(1.65)$ & $76.22(1.66)$ \\
non-HDL-C-mg/dL (SE) & 408 & $149.18(5.28)$ & $155.17(8.26)$ \\
GGT-U/L (SE) & 396 & $37.59(6.46)$ & $39.91(4.65)$ \\
\hline
\end{tabular}

\subsection{Percentage of Adults with Markers above Exposure Levels of $B L L>5 \mu g / d L$}

The data was explored at clinically relevant thresholds of SBP $>120 \mathrm{mmHg}$ and DBP $>80 \mathrm{mmHg}$ for blood pressure, GGT above the median (18 U/L) for oxidative stress, and non-HDL-C $>160 \mathrm{mg} / \mathrm{dL}$ for heart disease risk. Data for the percentage of adults above the thresholds for each marker was computed. At the $5 \mu \mathrm{g} / \mathrm{dL}$ level, the percentage of adults above the threshold for SBP increased with increasing age group. For DBP, non-HDL-C, and GGT, there was an increase from young adulthood to middle-age.

For SBP at the at the $5 \mu \mathrm{g} / \mathrm{dL}$ level, there was a significant difference between young adults and middle-aged adults $(p<0.001)$. For DBP at the $5 \mu \mathrm{g} / \mathrm{dL}$ level, there was a statistically significant difference between young adults and middle-aged adults $(p=0.029)$. For non-HDL-C, at the $5 \mu \mathrm{g} / \mathrm{dL}$ level, there was a statistically significant difference between young adults and middle-aged adults $(p=0.002)$.

At the $5 \mu \mathrm{g} / \mathrm{dL}$ and above level for GGT, there was a statistically significant difference between young adults and middle-aged adults $(p=0.006)$. Results for the percentage of adults above the thresholds for each marker are shown in Table 3 below.

Table 3. Percentage of adults above the clinical threshold for the markers of interest.

\begin{tabular}{cccc}
\hline Variables at $\mathbf{5} \boldsymbol{\mu g} / \mathbf{d L}$ & N Total & Young Adults (SE) & Middle-Aged Adults (SE) \\
\hline SBP-mmHg (SE) & 379 & $34.39(6.51)$ & $64.68(4.93)$ \\
DBP-mmHg (SE) & 379 & $13.32(5.71)$ & $29.11(5.15)$ \\
non-HDL-C-mg/dL (SE) & 408 & $68.23(6.40)$ & $90.33(2.41)$ \\
GGT-U/L (SE) & 396 & $62.24(6.98)$ & $82.71(3.85)$ \\
\hline
\end{tabular}

\subsection{Likelihood of Elevated Clinical Markers by Age Group}

The likelihood of elevated clinical markers as defined by clinically relevant thresholds of exposure (SBP > $120 \mathrm{mmHg}$ and DBP > $80 \mathrm{~mm} \mathrm{Hg}$ for blood pressure, GGT above the median (18 U/L) for oxidative stress, and non-HDL-C $>160 \mathrm{mg} / \mathrm{dL}$ for heart disease risk) were explored via binary logistic regression. The clinical markers served as the dependent variables with the independent variable being the natural log transformation of blood lead levels. This was explored among young and middle-aged adults. Results can be found in Table 4 below:

Table 4. Logistic regression of markers of interest among adults.

\begin{tabular}{ccccc}
\hline $\begin{array}{c}\text { Variable of } \\
\text { Interest }\end{array}$ & $\begin{array}{c}\text { Young Adults (18-44 } \\
\text { Years) Adj. Odds } \\
\text { Ratio (95\% CI) }\end{array}$ & $\boldsymbol{p}$-Value & $\begin{array}{c}\text { Middle-Aged Adults } \\
\text { (45-65 Years) Adj. Odds } \\
\text { Ratio (95\% CI) }\end{array}$ & $\boldsymbol{p}$-Value \\
\hline SBP $^{* *}$ & $1.21(1.07-1.38)$ & 0.003 & $1.32(1.14-1.52)$ & $<0.001$ \\
DBP $^{* *}$ & $1.32(1.10-1.58)$ & 0.003 & $1.16(0.98-1.38)$ & 0.076 \\
non-HDL-C $^{*}$ & $1.58(1.45-1.72)$ & $<0.001$ & $1.50(1.31-1.71)$ & $<0.001$ \\
GGT $^{+}$ & $1.55(1.39-1.72)$ & $<0.001$ & $1.37(1.15-1.64)$ & 0.001 \\
\hline
\end{tabular}

** adjusted for gender, body mass index (BMI), income, ethnicity, alcohol consumption, and smoking; * adjusted for gender, BMI, income, and ethnicity; ${ }^{+}$adjusted for gender, BMI, income, ethnicity, and alcohol consumption. 


\section{Discussion}

Lead has a profound effect on cardiovascular health. Low-level lead exposure affects the public's health and cardiovascular health in adults $[28,33]$. In the United States, exposure occurs due to the legacy of lead in mediums such as water, paint, and soil, thereby keeping populations continuously exposed [34-36]. Among adults in the U.S., the workplace is the primary location where exposure occurs [33].

In this study examining young and middle-aged adults from the U.S., it was hypothesized that BLLs would be higher for middle-aged adults, as they were more likely to have endured a longer duration of exposure. The mean BLL was found to be higher in middle-aged adults than younger adults in this study. This potentially indicates that a longer duration of exposure has left this group with elevated BLLs, which has put them at risk of diseases such as cardiovascular disease. It is key to note that since BLL is a measure of mainly acute exposure with a half-life of 30 days in blood [37], it is a non-perfect measure.

Lead generally showed a trend of increased association with higher SBP in this study as age increased. With age comes increasing arterial stiffness [38], which plays a significant role higher blood pressure during aging. Studies of metals which examine the mechanisms of their involvement in cardiovascular pathology suggest that lead may potentially play a role in arterial stiffness [24]. This was suggested when comparing young adults to middle-aged adults in this study.

DBP showed a similar trend to SBP, although its association (as an elevated marker) was not significant in middle-aged adults—as it was for SBP. This may be due to different pathophysiological mechanisms for SBP and DBP [39]. Indeed, pathophysiological alterations in the arterial wall make older people more prone to conditions such as isolated systolic hypertension, as changes including endothelial dysfunction and elastin calcifications increase the risk [40]. Finally, previous studies have found, in both men and women, that increases in blood lead concentration are associated with an elevation in SBP and DBP [16].

Regarding cholesterol, studies have demonstrated that lead potentially plays a role in cholesterol dysfunction [8,41]. The mean value of non-HDL-C in this study was larger in middle-aged adults compared to young adults. In a study by MacLean and colleagues, non-HDL-C increased with age in men until around 54 when it peaked, while in women it increased more gradually until age 54 when it increased appreciably to exceed the values of men [34]. In this study, the odds of those with elevated non-HDL-C having high BLL was true for young and middle-aged adults.

The mean GGT level was larger in middle-aged adults compared to young adults. At all exposure levels, GGT generally did not vary much between the two age groups. Lee and co-authors found associations between blood lead and GGT in adults [42]. Serum GGT has also been associated with all-cause cardiovascular disease in older adults [43].

Among the adults, increasing levels of lead exposure generally pushed those individuals above the threshold for elevated clinical markers for the variables of interest. This potentially speaks to the role lead may play in many multifactorial diseases as-along with genetics, diet, and other factors-environmental exposure to lead may contribute to people being propelled toward various cardiovascular pathologies. Thus, it is very important to mitigate exposure to promote public health.

Potential adverse health outcomes in young and middle-aged adults occurred both above and below the epidemiological threshold of $5 \mu \mathrm{g} / \mathrm{dL}$. This potentially confirms that no level of lead is safe and that more must be done to mitigate or eliminate sources of lead exposure.

\section{Mitigation of Exposure}

While being aware of the fact that many of the cardiovascular diseases resulting partly from lead exposure are multifactorial, comprehensive approaches must be explored to mitigate exposure to protect public health. Adult exposure to lead occurs mainly in the workplace; thus, interventions to lessen the effects of lead exposure may begin there and must factor in the hierarchy of controls [44]. Mitigating other sources of exposure may include reducing lead levels in gasoline, paint, plumbing 
pipes, and food cans [6]. In addition, technological solutions to reduce lead emissions from smelting facilities can decrease the risk on populations, as can soil remediation and behavioral interventions such as hand washing [6]. Regarding health, chelation treatment, which reduces the body burden of those with high BLLs, is an effective means to reduce risk [6].

A limitation of the study is the fact that measurement of BLLs represents short-term rather than longer-term exposure, as lead has a half-life of roughly 30 days in blood. Another limitation is the cross-sectional design, which makes it difficult to determine the temporal sequence of exposure and effect. Finally, a larger dataset would have allowed for examining older adults, who have presumably accumulated exposure over a longer period of time, but the amount of data for this group was too small to produce statistically reliable estimates for detailed demographic sub-domains.

\section{Conclusions}

Cardiovascular diseases are an issue of significant public health concern. Lead exposure affects cardiovascular markers in young and middle-aged adults, with higher exposure (with increasing age) generally resulting in worse health outcomes. Efforts must continue to stop exposure as early as pregnancy to prevent lead from accumulating and later affecting individuals into adulthood.

Funding: This research was funded from Emmanuel Obeng-Gyasi's research account provided by the United States Department of Education through its Title III initiative.

Acknowledgments: The National Center for Health Statistics and the U.S. Centers for Disease Control and Prevention (CDC) must be acknowledged for their invaluable work conducting the National Health and Nutrition Examination Survey in addition, the Division of Laboratory Sciences and the National Center for Environmental Health at the CDC must be acknowledged.

Conflicts of Interest: The author declares no conflict of interest.

\section{References}

1. Obeng-Gyasi, E. Lead Exposure and Oxidative Stress-A Life Course Approach in U.S. Adults. Toxics 2018, 6, 42. [CrossRef] [PubMed]

2. Obeng-Gyasi, E. Cholesterol and Oxidative Stress in US Pregnant Women Exposed to Lead. Med. Sci. 2019, 7,42 .

3. Obeng-Gyasi, E.; Obeng-Gyasi, B. Blood Pressure and Oxidative Stress among US Adults Exposed to Lead in Military Environments-A Preliminary Study. Diseases 2018, 6, 97. [CrossRef] [PubMed]

4. Qu, C.; Wang, S.; Ding, L.; Zhang, M.; Wang, D.; Giesy, J.P. Spatial distribution, risk and potential sources of lead in soils in the vicinity of a historic industrial site. Chemosphere 2018, 205, 244-252. [CrossRef] [PubMed]

5. da Rocha Silva, J.P.; Salles, F.J.; Leroux, I.N.; da Silva Ferreira, A.P.S.; da Silva, A.S.; Assunção, N.A.; Nardocci, A.C.; Sato, A.P.S.; Barbosa, F., Jr.; Cardoso, M.R.A. High blood lead levels are associated with lead concentrations in households and day care centers attended by Brazilian preschool children. Environ. Pollut. 2018, 239, 681-688. [CrossRef] [PubMed]

6. Obeng-Gyasi, E. Sources of lead exposure in various countries. Rev. Environ. Health 2019, 34, 25-34. [CrossRef]

7. Obeng-Gyasi, E.; Armijos, R.X.; Weigel, M.M.; Filippelli, G.; Sayegh, M.A. Hepatobiliary-Related Outcomes in US Adults Exposed to Lead. Environments 2018, 5, 46. [CrossRef]

8. Obeng-Gyasi, E.; Armijos, R.X.; Weigel, M.M.; Filippelli, G.M.; Sayegh, M.A. Cardiovascular-Related Outcomes in US Adults Exposed to Lead. Int. J. Environ. Res. Public Health 2018, 15, 759. [CrossRef]

9. Mishra, K. Lead exposure and its impact on immune system: A review. Toxicol. In Vitro 2009, 23, 969-972. [CrossRef]

10. Shih, R.; Glass, T.; Bandeen-Roche, K.; Carlson, M.; Bolla, K.; Todd, A.; Schwartz, B. Environmental lead exposure and cognitive function in community-dwelling older adults. Neurology 2006, 67, 1556-1562. [CrossRef]

11. Carter, H.E.; Schofield, D.; Shrestha, R. Productivity costs of cardiovascular disease mortality across disease types and socioeconomic groups. Open Heart 2019, 6, e000939. [CrossRef] [PubMed] 
12. Hu, H.; Aro, A.; Payton, M.; Korrick, S.; Sparrow, D.; Weiss, S.T.; Rotnitzky, A. The relationship of bone and blood lead to hypertension: The Normative Aging Study. JAMA 1996, 275, 1171-1176. [CrossRef] [PubMed]

13. Nash, D.; Magder, L.; Lustberg, M.; Sherwin, R.W.; Rubin, R.J.; Kaufmann, R.B.; Silbergeld, E.K. Blood lead, blood pressure, and hypertension in perimenopausal and postmenopausal women. JAMA 2003, 289, 1523-1532. [CrossRef] [PubMed]

14. Navas-Acien, A.; Guallar, E.; Silbergeld, E.K.; Rothenberg, S.J. Lead exposure and cardiovascular disease: A systematic review. Environ. Health Perspect. 2007, 115, 472-482. [CrossRef]

15. Hertz-Picciotto, I.; Croft, J. Review of the relation between blood lead and blood pressure. Epidemiol. Rev. 1993, 15, 352-373. [CrossRef]

16. Nawrot, T.; Thijs, L.; Den Hond, E.; Roels, H.; Staessen, J.A. An epidemiological re-appraisal of the association between blood pressure and blood lead: A meta-analysis. J. Human Hypertens. 2002, 16, 123. [CrossRef]

17. Lu, W.; Resnick, H.E.; Jablonski, K.A.; Jones, K.L.; Jain, A.K.; Howard, W.J.; Robbins, D.C.; Howard, B.V. Non-HDL cholesterol as a predictor of cardiovascular disease in type 2 diabetes: The strong heart study. Diabetes Care 2003, 26, 16-23. [CrossRef]

18. Blaha, M.J.; Blumenthal, R.S.; Brinton, E.A.; Jacobson, T.A. The importance of non-HDL cholesterol reporting in lipid management. J. Clin. Lipidol. 2008, 2, 267-273. [CrossRef]

19. Nantsupawat, N.; Booncharoen, A.; Wisetborisut, A.; Jiraporncharoen, W.; Pinyopornpanish, K.; Chutarattanakul, L.; Angkurawaranon, C. Appropriate Total cholesterol cut-offs for detection of abnormal LDL cholesterol and non-HDL cholesterol among low cardiovascular risk population. Lipids Health Disease 2019, 18, 28. [CrossRef]

20. Kojima, M.; Nemoto, K.; Murai, U.; Yoshimura, N.; Ayabe, Y.; Degawa, M. Altered gene expression of hepatic lanosterol 14a-demethylase (CYP51) in lead nitrate-treated rats. Arch. Toxicol. 2002, 76, 398-403. [CrossRef]

21. Lee, D.-H.; Blomhoff, R.; Jacobs, D.R. Review is serum gamma glutamyltransferase a marker of oxidative stress? Free Radical Res. 2004, 38, 535-539. [CrossRef] [PubMed]

22. Lim, J.-S.; Yang, J.-H.; Chun, B.-Y.; Kam, S.; Jacobs, D.R., Jr.; Lee, D.-H. Is serum $\gamma$-glutamyltransferase inversely associated with serum antioxidants as a marker of oxidative stress? Free Radical Biol. Med. 2004, 37, 1018-1023. [CrossRef] [PubMed]

23. Rahal, A.; Kumar, A.; Singh, V.; Yadav, B.; Tiwari, R.; Chakraborty, S.; Dhama, K. Oxidative stress, prooxidants, and antioxidants: The interplay. Biomed. Res. Int. 2014, 2014, 761264. [CrossRef] [PubMed]

24. Vaziri, N.D. Mechanisms of lead-induced hypertension and cardiovascular disease. Am. J. Physiol. Heart Circ. Physiol. 2008, 295, H454-H465. [CrossRef]

25. Reference Blood Lead Level for Adults. Available online: https://www.cdc.gov/niosh/topics/ables/description. html (accessed on 8 October 2019).

26. Reuben, A.; Caspi, A.; Belsky, D.W.; Broadbent, J.; Harrington, H.; Sugden, K.; Houts, R.M.; Ramrakha, S.; Poulton, R.; Moffitt, T.E. Association of childhood blood lead levels with cognitive function and socioeconomic status at age 38 years and with IQ change and socioeconomic mobility between childhood and adulthood. JAMA 2017, 317, 1244-1251. [CrossRef]

27. Beckley, A.L.; Caspi, A.; Broadbent, J.; Harrington, H.; Houts, R.M.; Poulton, R.; Ramrakha, S.; Reuben, A.; Moffitt, T.E. Association of childhood blood lead levels with criminal offending. JAMA Pediatr. 2018, 172, 1661-1673. [CrossRef]

28. Lanphear, B.P.; Rauch, S.; Auinger, P.; Allen, R.W.; Hornung, R.W. Low-level lead exposure and mortality in US adults: A population-based cohort study. Lancet Public Health 2018, 3, e177-e184. [CrossRef]

29. Mehta, G.; Macdonald, S.; Cronberg, A.; Rosselli, M.; Khera-Butler, T.; Sumpter, C.; Al-Khatib, S.; Jain, A.; Maurice, J.; Charalambous, C. Short-term abstinence from alcohol and changes in cardiovascular risk factors, liver function tests and cancer-related growth factors: A prospective observational study. BMJ Open 2018, 8, e020673. [CrossRef]

30. Mozaffarian, D.; Benjamin, E.J.; Go, A.S.; Arnett, D.K.; Blaha, M.J.; Cushman, M.; Das, S.R.; De Ferranti, S.; Després, J.P.; Fullerton, H.J. Heart disease and stroke statistics-2016 update a report from the American Heart Association. Circulation 2016, 133, e38-e48.

31. McCrindle, B.W. Cardiovascular consequences of childhood obesity. Can. J. Cardiol. 2015, 31, 124-130. [CrossRef] 
32. Safford, M.M.; Brown, T.M.; Muntner, P.M.; Durant, R.W.; Glasser, S.; Halanych, J.H.; Shikany, J.M.; Prineas, R.J.; Samdarshi, T.; Bittner, V.A. Association of race and sex with risk of incident acute coronary heart disease events. JAMA 2012, 308, 1768-1774. [CrossRef] [PubMed]

33. Lanphear, B.P.; Hornung, R.; Khoury, J.; Yolton, K.; Baghurst, P.; Bellinger, D.C.; Canfield, R.L.; Dietrich, K.N.; Bornschein, R.; Greene, T. Low-level environmental lead exposure and children's intellectual function: An international pooled analysis. Environ. Health Perspect. 2005, 113, 894. [CrossRef] [PubMed]

34. Bellinger, D.C. Lead contamination in Flint-An abject failure to protect public health. N. Engl. J. Med. 2016, 374, 1101-1103. [CrossRef] [PubMed]

35. Filippelli, G.; Adamic, J.; Nichols, D.; Shukle, J.; Frix, E. Mapping the Urban Lead Exposome: A Detailed Analysis of Soil Metal Concentrations at the Household Scale Using Citizen Science. Int. J. Environ. Res. Public Health 2018, 15, 1531. [CrossRef] [PubMed]

36. Laidlaw, M.; Filippelli, G.; Sadler, R.; Gonzales, C.; Ball, A.; Mielke, H. Children's blood lead seasonality in flint, Michigan (USA), and soil-sourced lead hazard risks. Int. J. Environ. Res. Public Health 2016, 13, 358. [CrossRef] [PubMed]

37. Barbosa, F., Jr.; Tanus-Santos, J.E.; Gerlach, R.F.; Parsons, P.J. A critical review of biomarkers used for monitoring human exposure to lead: Advantages, limitations, and future needs. Environ. Health Perspect. 2005, 113, 1669-1674. [CrossRef]

38. Franklin, S.S. Hypertension in older people: Part 1. J. Clin. Hypertens. 2006, 8, 444-449.

39. Franklin, S.S. Elderly hypertensives: How are they different? J. Clin. Hypertens. 2012, 14, 779-786. [CrossRef]

40. AlGhatrif, M.; Lakatta, E.G. The conundrum of arterial stiffness, elevated blood pressure, and aging. Curr. Hypertens. Rep. 2015, 17, 12. [CrossRef]

41. Ademuyiwa, O.; Ugbaja, R.N.; Idumebor, F.; Adebawo, O. Plasma lipid profiles and risk of cardiovascular disease in occupational lead exposure in Abeokuta, Nigeria. Lipids Health Dis. 2005, 4, 19. [CrossRef]

42. Lee, D.-H.; Lim, J.-S.; Song, K.; Boo, Y.; Jacobs, D.R., Jr. Graded associations of blood lead and urinary cadmium concentrations with oxidative-stress-related markers in the US population: Results from the Third National Health and Nutrition Examination Survey. Environ. Health Perspect. 2006, 114, 350. [CrossRef] [PubMed]

43. Loomba, R.; Doycheva, I.; Bettencourt, R.; Cohen, B.; Wassel, C.L.; Brenner, D.; Barrett-Connor, E. Serum $\gamma$-glutamyltranspeptidase predicts all-cause, cardiovascular and liver mortality in older adults. J. Clin. Exp. Hepatol. 2013, 3, 4-11. [CrossRef] [PubMed]

44. NIOSH. HIERARCHY OF CONTROLS. Available online: https://www.cdc.gov/niosh/topics/hierarchy/ (accessed on 8 October 2019). 